\title{
Traditional Japanese Style Bathing May Contribute to Good Health and Longevity
}

\author{
Mayumi Watanabe $^{1^{*}}$, Shigeharu Koboshi², Hiroshi Yoshimoto ${ }^{2}$, Kazuhiro Kobayashi², \\ Chikako Tomiyama ${ }^{3}$, Toru Abo ${ }^{4}$ \\ ${ }^{1}$ Department of Medical Informatics, Niigata University Medical and Dental Hospital, Niigata, Japan \\ ${ }^{2}$ Hot Album Tansansen Tablet, Inc., Hachiouji, Japan \\ ${ }^{3}$ Department of Medical Technology, Graduate School of Health Sciences, Niigata University, Niigata, Japan \\ ${ }^{4}$ Toru Abo Research Centre, Niigata, Japan \\ Email: *watanabem62@gmail.com
}

Received 26 February 2016; accepted 28 May 2016; published 31 May 2016

Copyright (C) 2016 by authors and Scientific Research Publishing Inc.

This work is licensed under the Creative Commons Attribution International License (CC BY).

http://creativecommons.org/licenses/by/4.0/

(c) (i) Open Access

\section{Abstract}

The objective of this study was to determine how traditional Japanese style bathing could promote good health. Using healthy volunteers, we assessed body temperature (core and cutaneous), red blood cells, white blood cells (WBCs), venous blood gas parameters $\left(\mathrm{PO}_{2}, \mathrm{SO}_{2}, \mathrm{PCO}_{2}, \mathrm{TCO}_{2}, \mathrm{HCO}_{3}\right.$, and $\mathrm{pH}$ ), weight loss (which may indicate sweat volume), and the time until sweating before and after bathing. We simultaneously conducted a double-blind clinical trial using a bath additive group and a control group to investigate the effect of a bath additive on the same parameters. We found that bathing increased the core and cutaneous body temperature, as well as $\mathrm{PO}_{2}, \mathrm{SO}_{2}$, and blood pH. All of the subjects also showed increases in heart rate and weight loss (sweat volume). After bathing, the number and ratio of granulocytes increased while the number and ratio of lymphocytes decreased. These results tended to be emphasized in the bath additive group; however, significant between-group differences were not detected. Our results indicated that bathing improved blood circulation and had a modulatory effect on the autonomic nervous system. This suggested that traditional Japanese style bathing might contribute to good health and longevity; however, additional larger-scale studies were needed to confirm or refute this conclusion.

\section{Keywords}

Body Temperature, Bathing, Bath Additive, Blood Gas, Heart Rate, Sweat

\footnotetext{
"Corresponding author.
}

How to cite this paper: Watanabe, M., Koboshi, S., Yoshimoto, H., Kobayashi, K., Tomiyama, C. and Abo, T. (2016) Traditional Japanese Style Bathing May Contribute to Good Health and Longevity. Health, 8, 756-763. 


\section{Introduction}

According to the Ministry of Health, Labour and Welfare, Japan, Japanese women had the longest average life expectancy worldwide, at 86.83 years, for the third consecutive year in 2014, while Japanese men climbed a notch to tie for third longest life expectancy at 80.50 years [1] [2]. Many researchers have looked for explanations for the longevity of modern Japanese people, and one aspect of the Japanese lifestyle that has captured their attention is the tradition of taking regular hot water baths [3]-[5]. Japanese people have loved bathing in hot springs since ancient times, expecting anti-ageing effects from the hyperthermia of the water and from active ingredients (such as sulfur or carbon dioxide) contained within it [6].

Most Japanese people take baths frequently. The American anthropologist Ruth Benedict reported in her book on Japanese culture, "One of the best loved minor pleasures of the body in Japan is the hot bath...the daily soak in superlatively heated water is a part of the routine of every late afternoon... They sit in the bath with their knees drawn up in fetal position, the water up to their chins" [7]. As she observed, the purpose of this bathing is not only to wash the body with water but also to enjoy the therapeutic effects of hyperthermia. This custom continues in modern Japan, where $80 \%$ of young people ( $<40$ years old) bathe in a tub everyday while only $3 \%$ of them prefer showers [8]. A recent investigation in Japan found that $27.6 \%$ of respondents put additives into their bath water to enjoy hot spring-like effects [9].

In the present study, we investigated the health effects of the hyperthermia and bath additives associated with traditional Japanese style bathing. Pre- and post-bath body temperature (core and cutaneous), red blood cell counts, white blood cell (WBC) counts and ratios, venous blood gas parameters $\left(\mathrm{PO}_{2}, \mathrm{SO}_{2}, \mathrm{PCO}_{2}, \mathrm{TCO}_{2}, \mathrm{HCO}_{3}\right.$, and $\mathrm{pH}$ ), and sweat parameters (volume and time until sweating) were measured. The effects of a bath additive on these parameters were also assessed.

\section{Materials and Methods}

\subsection{Subjects}

Six healthy volunteers, aged 23 to 60 years (average $40.8 \pm 17.0$ years), participated in this study. Written informed consent was obtained from all subjects and the study was approved by the institutional review board of the Yushima Shimizuzaka Clinic (Tokyo, Japan). The experiments were conducted at a constant temperature of $25.0^{\circ} \mathrm{C} \pm 0.5^{\circ} \mathrm{C}$ and humidity of $50.0 \% \pm 5.0 \%$, except during the bathing time.

\subsection{Double-Blind Clinical Trial with Bath Additive}

The subjects were divided randomly into two groups, a control group and a bath additive (BA) group (n = 3/ group). The control group bathed in regular hot tap water. The BA group bathed in hot tap water with a bath additive (Sparkling Hot Tab, Hot Album Tansansen Tablet, Inc. Hachiouji, Japan). This bath additive, which contains sodium bicarbonate mixed with citric acid, generates carbon dioxide in the water, causing effervescence like a naturally carbonated spring. It is colorless, bland and innocuous and produced carbon dioxide gas is too small to be recognized by the naked eye. This study was a double-blind clinical trial; therefore, the subjects did not know which bath they took.

\subsection{Kinetic Analysis of Core and Cutaneous Body Temperature}

All subjects rested for more than 20 minutes before bathing for 15 minutes at a water temperature of $40^{\circ} \mathrm{C} \pm$ $0.5^{\circ} \mathrm{C}$. Core temperature was measured at the axilla with a clinical mercury thermometer (FAVOR, Nihon Keiryoki Kogyo Co. Ltd., Chiyoda, Japan). Cutaneous body temperature was measured using a contactless digital thermometer (Microlife, IR 1DA1, Microlife, Switzerland) at five previously described peripheral locations: Yintang (on the forehead, midway between the medial ends of the eyebrows), LI4 (Hegu; on the dorsum of the right and left hands, radial to the mid-point of the second metacarpal bone), LR3 (Taichong; on the dorsum of the right and left feet, between the first and second metatarsal bones, in the depression distal to the junction of the bases of the two bones, over the dorsalis pedis artery) [10].

Kinetic body temperature was measured before bathing and at 0, 20, 40, and 60 minutes after bathing as described previously [11]. Cutaneous body temperature was monitored before bathing and 0 and 60 minutes after 
bathing.

\subsection{Assessment of Blood Parameters}

Fresh venous blood obtained from the median antebrachial vein before and after bathing was used to measure the partial pressures of oxygen and carbon dioxide $\left(\mathrm{PO}_{2}\right.$ and $\left.\mathrm{PCO}_{2}\right)$, oxygen saturation $\left(\mathrm{SO}_{2}\right)$, total carbon dioxide $\left(\mathrm{TCO}_{2}\right)$, hydrogen carbonate $\left(\mathrm{HCO}_{3}\right)$,and red blood cell count using an i-STAT $300 \mathrm{~F}$ (i-STAT Corporation, East Windsor, NJ, USA) as previously described [10] [12] [13]. WBCs were counted using a hemocytometer and the May-Grünwald-Giemsa stain method (Nihon Novamed. Co., Ltd, Tokyo, Japan).

\subsection{Heart Rate and Sweat Measurements}

The subjects measured their own heart rate and time before sweating. The volume of sweat was calculated from the change in body weight (before experiment -0 minutes after bathing).

\subsection{Statistical Analysis}

The statistical significance of differences between values was tested with statistical software Statcel2(OMS Publishing, Saitama, Japan), which is written in Visual Basic for Applications, using paired $t$-tests or repeatedmeasures two-factor ANOVA with Bonferroni/Dunn post-hoc tests. $P$ values of less than 0.05 were considered to be statistically significant.

\section{Results}

\subsection{Body Temperature}

\subsubsection{Core Temperature}

Core temperature was measured before bathing and tracked for 60 minutes after bathing. During the bath (before experiment- 0 minutes after bathing), the mean core temperature increased (from $36.0^{\circ} \mathrm{C} \pm 0.6^{\circ} \mathrm{C}$ to $36.9^{\circ} \mathrm{C} \pm$ $0.5^{\circ} \mathrm{C} ; P<0.05$ ), the temperature then decreased to $36.2^{\circ} \mathrm{C} \pm 0.6^{\circ} \mathrm{C}$ at 60 minutes after the bath. Thus, bathing resulted in a rapid increase in core temperature. In the control group, core temperature had returned to baseline levels $\left(35.7^{\circ} \mathrm{C} \pm 0.2^{\circ} \mathrm{C}\right.$ ) by 60 min after bathing, while in the BA group the core temperature tended to remain elevated for longer $\left(36.6^{\circ} \mathrm{C} \pm 0.5^{\circ} \mathrm{C}\right.$ at $60 \mathrm{~min}$ after bathing). However, these between-group differences did not reach statistical significance, likely because of the small group sizes (Figure 1).

\subsubsection{Cutaneous Temperature}

It has been reported that rapid changes in core temperature are associated with changes in cutaneous blood flow mediated by the autonomic nervous system [14]; therefore, we measured cutaneous body temperature over time at five locations. Soon after bathing, the temperature of the hands and feet increased (average: hands, $1.3^{\circ} \mathrm{C} \pm$ $0.6^{\circ} \mathrm{C}$; feet, $4.9^{\circ} \mathrm{C} \pm 1.5^{\circ} \mathrm{C}$ ). The cutaneous temperature of the hands recovered after 60 minutes, but the temperature of the feet remained $1.7^{\circ} \mathrm{C} \pm 1.5^{\circ} \mathrm{C}$ higher than before bathing. However, these changes were not statistically significant $(P>0.05$; Figure 2$)$.

\subsection{Various Blood Gases Parameters}

Because an increase in heart rate might affect blood circulation and thereby cause a decrease in the oxygen content of venous blood, we measured the partial pressures of oxygen and carbon dioxide $\left(\mathrm{PO}_{2}\right.$ and $\left.\mathrm{PCO}_{2}\right)$, oxygen saturation $\left(\mathrm{SO}_{2}\right)$, total carbon dioxide $\left(\mathrm{TCO}_{2}\right)$, and hydrogen carbonate $\left(\mathrm{HCO}_{3}\right)$. We found that $\mathrm{PO}_{2}$ and $\mathrm{SO}_{2}$ both increased after bathing (from $30 \pm 8$ to $60 \pm 14 \mathrm{mmHg}$ and from $51.3 \% \pm 15.9 \%$ to $87.7 \% \pm 10.1 \%$, respectively). The $\mathrm{pH}$ simultaneously increased from $7.33 \pm 0.03$ to $7.38 \pm 0.01$. However, $\mathrm{PCO}_{2}, \mathrm{TCO}_{2}$, and $\mathrm{HCO}_{3}$ did not change significantly with bathing.

When the control and BA groups were compared, subjects in the BA group tended to have larger changes in both $\mathrm{PO}_{2}$ (control group vs BA group: from $30 \pm 10$ to $49 \pm 11$ vs from $30 \pm 6$ to $71 \pm 9 \mathrm{mmHg}$. respectively) and $\mathrm{SO}_{2}$ (from $49.0 \% \pm 22.6 \%$ to $81.3 \% \pm 11.5 \%$ vs from $53.7 \% \pm 10.1 \%$ to $94.0 \% \pm 1.0 \%$, respectively (Figure 3). However, these apparent changes from baseline were not statistically significant due to high inter-subject variability (data not shown). 


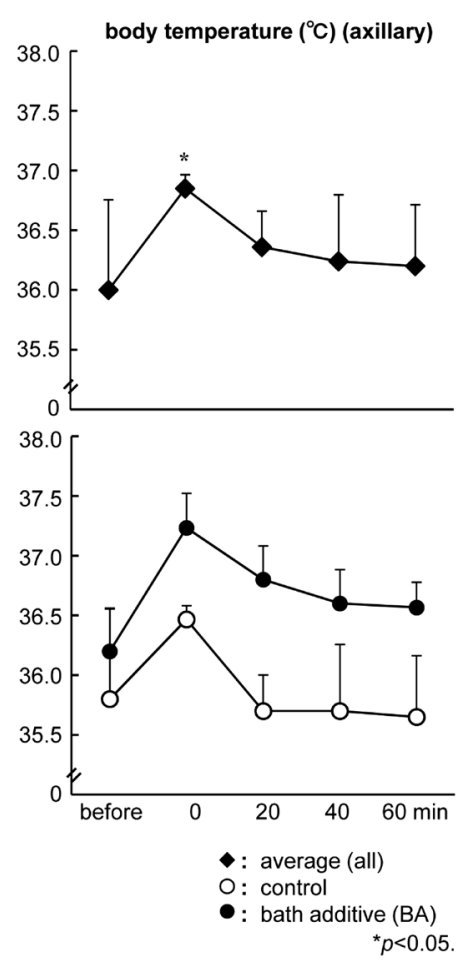

Figure 1. Core temperature was measured before bathing and tracked for 60 minutes after bathing. Bathing caused a rapid increase in core temperature (from $36.0^{\circ} \mathrm{C} \pm 0.6^{\circ} \mathrm{C}$ to $36.9^{\circ} \mathrm{C} \pm 0.5^{\circ} \mathrm{C}$; $P<0.05$ ). The core temperature of the control group had recovered at 60 minutes after bathing while the core temperature of the BA group tended to remain higher than before bathing.

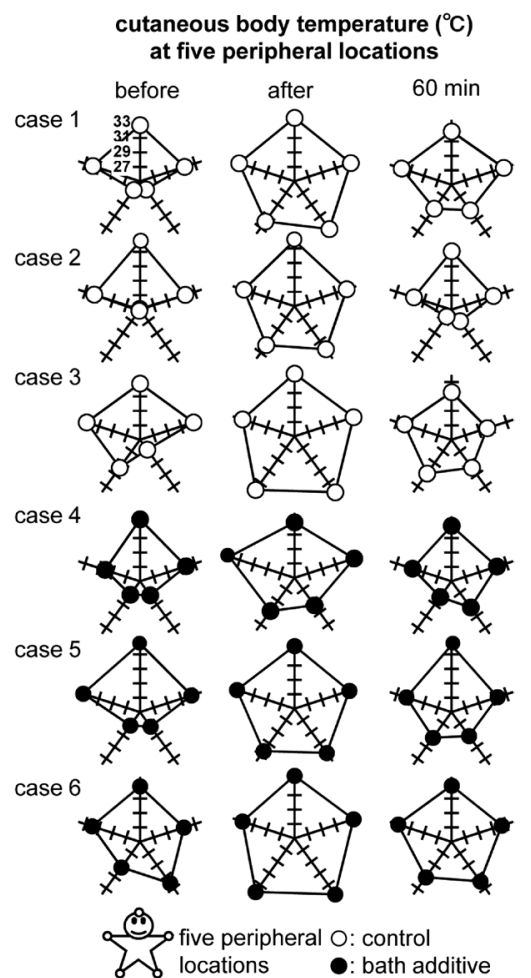

Figure 2. Cutaneous temperature was measured at five peripheral locations. Soon after bathing, the temperature of the hands and feet increased in all participants. 

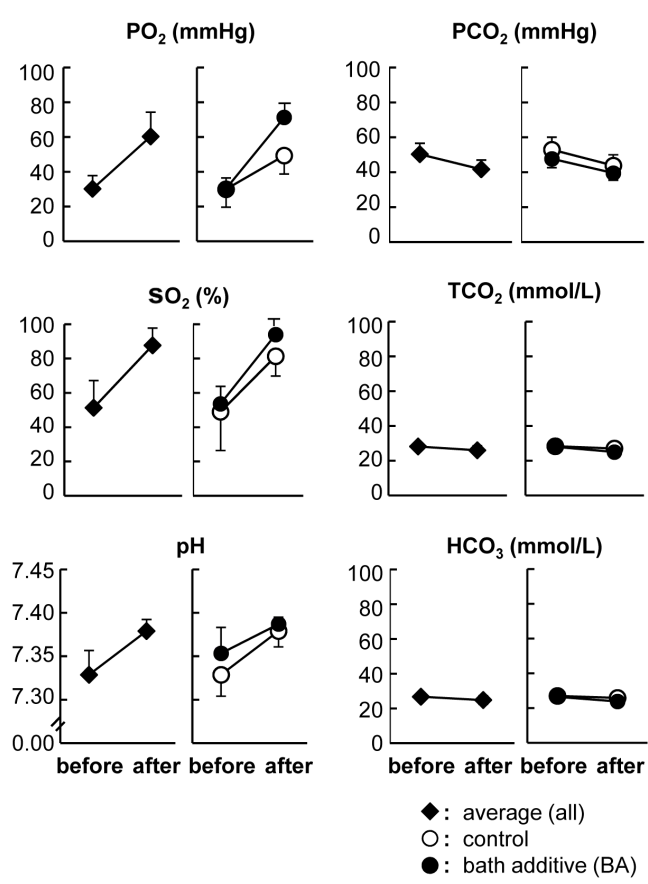

Figure 3. $\mathrm{PO}_{2}, \mathrm{SO}_{2}$ and $\mathrm{pH}$ were elevated after bathing. The $\mathrm{BA}$ group tended to show a greater change in $\mathrm{PO}_{2}$ and $\mathrm{SO}_{2}$.

\subsection{White Blood Cell Counts and Ratios}

To investigate the effect of bathing on immune function and the status of the autonomic nervous system, WBC counts and ratios were determined before and after bathing. After bathing, the ratio of granulocytes increased from $58 \% \pm 12 \%$ to $64 \% \pm 12 \%$, while the lymphocyte ratio tended to decrease (from $37 \% \pm 12 \%$ to $30 \% \pm$ $11 \%)$. The absolute numbers of granulocytes and lymphocytes were also determined and, although they showed the same tendency, there was no statistically significant effect of bathing on WBC counts (Figure 4).

The granulocyte response to bathing tended to be higher in the BA group than the control group; however, this difference was not statistically significant due to high inter-subject variability (data not shown) (Figure 4).

\subsection{Heart Rate and Sweat}

An increase in body temperature, such as that caused by bathing or exercise, elevates the heart rate and causes sweating. Therefore, heart rate and sweat parameters (the volume of sweat and the time until sweating) were assessed. All subjects experienced increases in heart rate and all began sweating during the bath (heart rate: from $78 \pm 18$ to $91 \pm 15 / \mathrm{min}$, weight loss (sweat volume): $80 \pm 84 \mathrm{~g}$, time before sweating: $9 \pm 4 \mathrm{~min}$ ). Subjects in the BA group lost sweat more $(150 \pm 71$ vs $33 \pm 58 \mathrm{~mL})$ and sooner ( $8 \pm 3$ vs $10 \pm 5 \mathrm{~min})$ than those in the control group (Figure 5).

\section{Discussion}

\subsection{Bathing Elevated $\mathrm{pH}, \mathrm{SO}_{2}, \mathrm{PO}_{2}$, and Body Temperature}

Bathing induced changes in various blood parameters, including increases in $\mathrm{SO}_{2}, \mathrm{PO}_{2}$, and $\mathrm{pH}$ in the venous blood (Figure 3). The concomitant increases in both core and cutaneous body temperature and heart rate (Figure 5) are likely owing to circulatory improvements caused by bathing. We observed that the face color of all subjects changed from pale to red during their bath, and that the color of their venous blood changed from dark red to vivid red after bathing, as we have previously reported [4]. These observations may indicate an increased amount of hemoglobin-bound oxygen, resulting in the alkalization of venous blood. The simultaneous increase in heart rate also indicates promotion of circulatory function. 

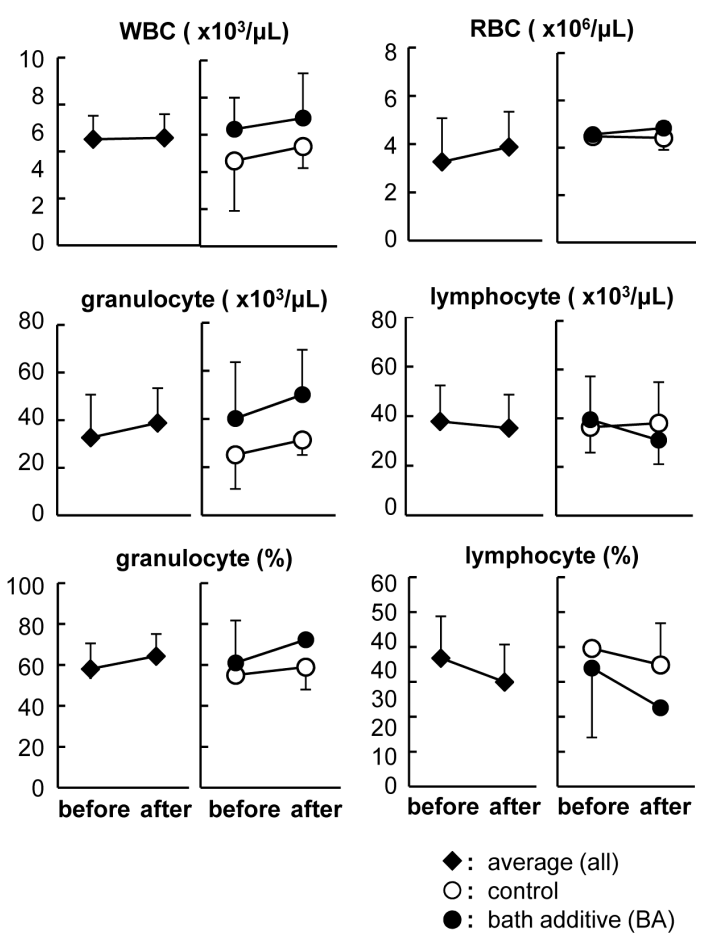

Figure 4. After bathing, the granulocyte ratio increased while the lymphocyte ratio decreased. The granulocyte response to bathing tended to be greater in the BA group than in the control group.

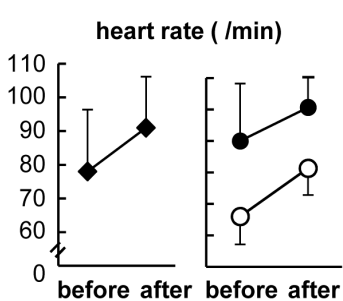

: average (all)

O: control

: bath additive (BA)

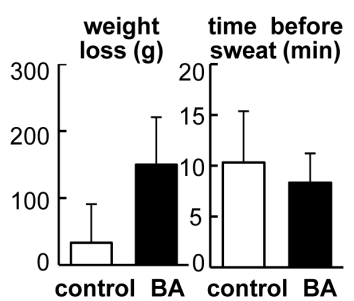

$\square$ : control

: bath additive (BA)

Figure 5. Heart rate, weight loss and sweat measurements. Heart rate increased in all subjects during the bath and all subjects started sweating. Subjects in the BA group lost more weight and sweat sooner than subjects in the control group.

The increases in body temperature, $\mathrm{SO}_{2}$, and $\mathrm{PO}_{2}$ tended to be greater in the $\mathrm{BA}$ group than in the control group; however, these differences were not significant (Figure 3 and Figure 5). It is possible that the bath additive, which generates carbon dioxide in hot water, may stimulate the skin or the subcutaneous capillaries. This stimulation may have excited parasympathetic nerves causing further improvements in peripheral blood flow. In this manner, the chemical $\left(\mathrm{CO}_{2}\right)$ stimulation of a bath additive may augment the heat stimulation of the hot water and thus increase the beneficial effects of bathing. However, further investigations, including assessments of respiratory rate, are needed to determine if this is the case.

\subsection{Granulocytes Increased and Lymphocytes Decreased after Bathing}

Our results showed that the number and the ratio of granulocytes increased after bathing, while the number and 
ratio of lymphocytes decreased. WBCs can be categorized into two types: those that adhere to the blood vessel walls and those that flow freely through the blood vessels. Granulocytes, which increased with the stimulation of bathing, are in the former category [15] [16]. Similar results have been observed after acupuncture treatment, which has modulatory effects on the autonomic nervous system [10].

Both bathing and acupuncture stimulate the body surface, through the application of mild heat and pain, respectively. Acupuncture has been known to effectively promote good health for thousands of years [17]-[21]. Our results suggest that traditional Japanese style bathing may also contribute to good health and longevity by improving blood circulation and through modulatory effects on the autonomic nervous system. For example, some studies have shown that bathing, which increases body temperature and oxygenation by improving circulation, may effectively prevent the onset of cancer, which occurs under the stressful conditions of hypothermia and hypoxia [13] [22]. However, we used a limited number of subjects in this small size clinical report and therefore additional larger scale studies are required to further support the findings that we report here. Observation of longer-term repetitive bathing using age-matched groups would also provide valuable information regarding the potentially beneficial effects of Japanese style bathing on health.

\section{Conclusion}

Bathing increased venous blood $\mathrm{pH}, \mathrm{SO}_{2}$, and $\mathrm{PO}_{2}$, as well as body temperature (core and cutaneous) and heart rate. Moreover, the use of a bath additive tended to increase the oxygenation of venous blood, had modulatory effects on the autonomic nervous system, and promoted sweating. These would be valuable factors to assess in any future larger scale studies on the health benefits of bathing.

\section{Acknowledgements}

Special thanks to Mr. Taiki Hashimoto, and Ms. Kaori Yamamoto (Yushima-Shimizuzaka Clinic, Tokyo, Japan) for their work on the preparation of this study. In addition, we thank Mr. Tadao Aono, Mr. Takenori Shida, and Ms. Risa Namose (Fuso Pharmaceutical Industries, Ltd, Tokyo, Japan) for their valuable advice, especially regarding the blood gas analyses. The authors also thank all of the volunteers who participated in this study.

\section{References}

[1] Japanese Ministry of Health, Labour and Welfare (2015) Simple Life Table. Japanese Ministry of Health, Labour and Welfare. http://www.mhlw.go.jp/toukei/saikin/hw/life/life14/dl/life14-04.pdf

[2] Japanese Ministry of Health, Labour and Welfare (2015) International Comparison. Japanese Ministry of Health, Labour and Welfare. http://www.mhlw.go.jp/toukei/saikin/hw/life/life14/dl/life14-15.pdf

[3] Ogawa, M., Tamura, T., Shouji, K., Ohta, M., Kimura, Y. and Togawa, T. (1999) An Attempt of Unconstraint Heart and Respiratory Measurement by Using Photoplethysmograph for Home Health Monitoring. Technical Report of IEICE. MBE, 90, 37-40.

[4] Ohishi, T., Nukuzuma, C., Seki, A., Watanabe, M., Tomiyama-Miyaji, C., Kainuma, E., Inoue, M., Kuwano, Y. and Abo, T. (2009) Alkalization of Blood pH Is Responsible for Survival of Cancer Patients by Mild Hyperthermia. Biomedical Research, 30, 95-100.

[5] Tomiyama-Miyaji, C., Watanabe, M., Ohishi, T., Kanda, Y., Kainuma, E., Bakir, H.Y., Shen, J., Ren, H., Inoue, M., Tajima, K., Bai, X. and Abo, T. (2007) Modulation of the Endocrine and Immune Systems by Well-Controlled Hyperthermia Equipment. Biomedical Research, 28, 119-125. http://dx.doi.org/10.2220/biomedres.30.95

[6] Matsuda, N. (2015) Japan’s Hot-Spring Tradition. Professor Onsen’s Top Hot Springs, Nippon Communications Foundation. http://www.nippon.com/en/views/b04703/

[7] Benedict, R. (1989) The Circle of Human Feelings In: Benedict, R., Ed, The Chrysanthemum and the Sword: Patterns of Japanese Culture, Houghton Miffin Company, 177-194.

[8] Osaka Gas Co., Ltd. (2004) Press Release 03-15-Younger Generation (<40 years old) Prefers Tub than Shower. https://www.osakagas.co.jp/company/press/pr_2004/03-15.html

[9] Panasonic Corporation (2013) The Purpose and Style When You Bathe. http://sumai.panasonic.jp/sumai_create/enq/002.html

[10] Watanabe, M., Takano, O., Tomiyama, C., Matsumoto, H., Urahigashi, N., Kainuma, E., Madarame, T., Fukuda, M. and Abo, T. (2012) The Effects of Application of an Ancient Type of Acupuncture Needle on Body Temperature, Immune Function and the Autonomic Nerve System. Health, 4, 775-780. http://dx.doi.org/10.4236/health.2012.410120 
[11] Tomiyama, C., Watanabe, M., Honma, T., Inada, A., Hayakawa, T., Ryufuku, M. and Abo, T. (2015) The Effect of Repetitive Mild Hyperthermia on Body Temperature, the Autonomic Nervous System, and Innate and Adaptive Immunity. Biomedical Research, 36, 135-142. http://dx.doi.org/10.2220/biomedres.36.135

[12] Watanabe, M., Takano, O., Tomiyama, C., Matsumoto, H., Kobayashi, T., Madarame, T. and Abo, T. (2012) Skin Rubdown with a Dry Towel, "Kanpu-Masatsu”, Is an Aerobic Exercise. Biomedical Research, 33, 243-248. http://dx.doi.org/10.2220/biomedres.33.243

[13] Watanabe, M., Miyajima, K., Matsui, I., Tomiyama-Miyaji, C., Kainuma, E., Inoue, M., Matsumoto, H., Kuwano, Y. and Abo, T. (2010) Internal Environment in Cancer Patients and Proposal That Carcinogenesis Is Adaptive Response of Glycolysis to Overcome Adverse Internal Conditions. Health, 2, 781-788. http://dx.doi.org/10.4236/health.2010.27118

[14] Baker, M.A., Cronin, M.J. and Mountjoy, D.G. (1976) Variability of Skin Temperature in the Waking Monkey. American Journal of Physiology, 230, 449-455.

[15] Kainuma, E., Watanabe, M., Tomiyama-Miyaji, C., Inoue, M., Kuwano, Y., Ren, H. and Abo, T. (2009) Association of Glucocorticoid with Stress-Induced Modulation of Body Temperature, Blood Glucose and Innate Immunity. Psychoneuroendocrinology, 34, 1459-1468. http://dx.doi.org/10.1016/j.psyneuen.2009.04.021

[16] Watanabe, M., Tomiyama-Miyaji, C., Kainuma, E., Inoue, M., Kuwano, Y., Ren, H., Shen, J. and Abo, T. (2008) Role of Alpha-Adrenergic Stimulus in Stress-Induced Modulation of Body Temperature, Blood Glucose and Innate Immunity. Immunology Letters, 115, 43-49. http://dx.doi.org/10.1016/j.imlet.2007.09.010

[17] Watanabe, M., Kainuma, E. and Tomiyama, C. (2015) Repetitive Manual Acupuncture Increases Markers of Innate Immunity in Mice Subjected to Restraint Stress. Acupuncture in Medicine, 33, 312-318. http://dx.doi.org/10.1136/acupmed-2014-010660

[18] Watanabe, M., Takano, O., Tomiyama, C., Guan, J., Hou, G., Mori, H., Nishijo, K., Abo, T. and Akazwa, K. (2013) The Effects of Application of an Ancient Type of Acupuncture Needle on Increase in Urination of Hospitalized Oldest-Old People. Health, 5, 1092-1098. http://dx.doi.org/10.4236/health.2013.57147

[19] Kawakita, K., Shichidou, T., Inoue, E., Nabeta, T., Kitakoji, H., Aizawa, S., Nishida, A., Yamaguchi, N., Takahashi, N., Sumiya, E., Okada, K., Umeda, T., Yano, T. and Tanzawa, S. (2008) Do Japanese Style Acupuncture and Moxibustion Reduce Symptoms of the Common Cold? Evidence-Based Complementary and Alternative Medicine, 5, 481489. http://dx.doi.org/10.1093/ecam/nem055

[20] National Institude of Health (1997) Acupuncture. NIH Consensus Statement, 15, 1-34.

[21] World Health Organization (2002) Acupuncture: Review and Analysis of Reports on Controlled Clinical Trials. World Health Organization, Geneva.

[22] Watanabe, M., Matsumoto, H., Tomiyama, C., Akazawa, K. and Abo, T. (2011) Internal Environment for Growth of Cancer Cells in Mice: Hypothermia, Anemia and Lymphocytopenia. Health, 3, 238-244. http://dx.doi.org/10.4236/health.2011.34042 